\title{
Monitoring and analysis of the expansion of the Ajmr Port, Davao City, Philippines using multi-source remote sensing data
}

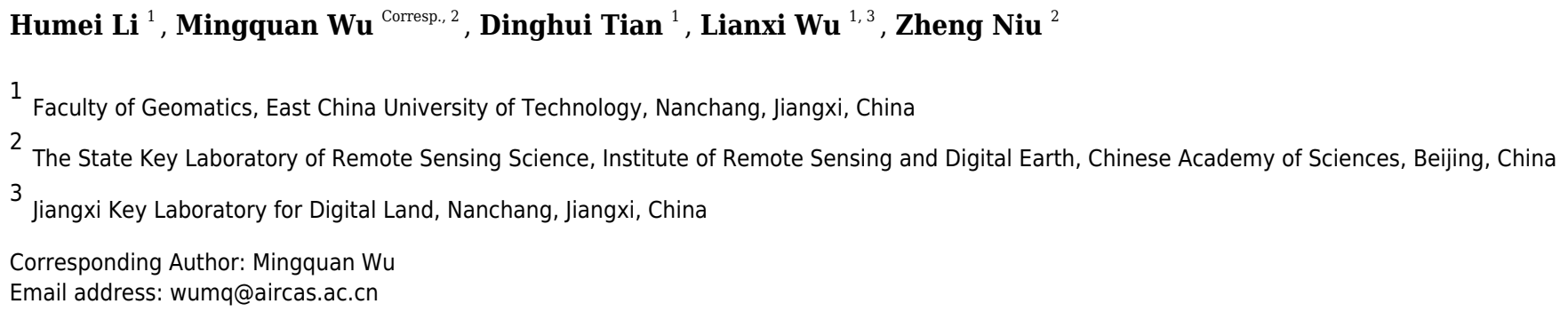

Ports have been built or expanded in a number of countries to cater to increasing maritime trade in the 21st century. Port expansion is associated with economic and environmental impacts on the local and regional scales, and these impacts can be studied using remote sensing. The present study presents new results from multi-source remote sensing monitoring of the Ajmr Port expansion. An analysis of land use and vegetation coverage at the port is used to monitor the impact of port construction on the local ecology, while changes in roads, buildings, and lights are used to monitor the economic impact. The results show that: (1)After nine years of expansion, the port area has gradually expanded from the central to the southern coastal area, with an increase of 21.68 hectares during the expansion period. After the expansion, the area of builidings and construction in the study area increased significantly, while the area of water and green areas decreased significantly, indicating that the port construction changed the land use structure of the area. (2) From the perspective of vegetation coverage, the vegetation coverage within 5 $\mathrm{km}$ from the port is in good condition. After 9 years, the vegetation coverage in the region between 0.6 and 1 increased from $43.71 \%$ to $44.25 \%$, reflecting the higher overall greening level in the region. (3) By analyzing the increase in roads and buildings, it can be seen that the port's comprehensive transportation capacity has improved, the population of the region has increased significantly. As the scale of construction has been continuously expanded, the prosperity as increased. (4) By analyzing the changes in the light index, the light data from the northeast to the southwest in the region is very obvious, and it is clearly located along the coast, indicating that the economic development of the coastal zone is faster than other regions, and the coastal region has promoted the development of the inland region. 
1 Monitoring and Analysis of the Expansion of the Ajmr

2 Port, Davao City, Philippines using Multi-source

3 Remote Sensing Data

5 Humei $\mathrm{Li}^{1}$, Mingquan $\mathrm{Wu}^{2}$, Dinghui Tian ${ }^{1}$, Lianxi $\mathrm{Wu}^{1,3}$, Zheng $\mathrm{Niu}^{2}$

6

$7{ }^{1}$ Faculty of Geomatics, East China University of Technology, Nanchang, Jiangxi, China

82 The State Key Laboratory of Remote Sensing Science, Institute of Remote Sensing and Digital

9 Earth, Chinese Academy of Sciences, Beijing, China

${ }^{3}$ Jiangxi Key Laboratory for Digital Land, Nanchang, Jiangxi, China

Corresponding Author:

Mingquan $\mathrm{Wu}^{2}$

Datun Road No. 20 North, Beijing, 100101, China

Email address:wumq@aircas.ac.cn

\section{Abstract}

Ports have been built or expanded in a number of countries to cater to increasing maritime trade in the 21 st century. Port expansion is associated with economic and environmental impacts on the local and regional scales, and these impacts can be studied using remote sensing. The present study presents new results from multi-source remote sensing monitoring of the Ajmr Port expansion. An analysis of land use and vegetation coverage at the port is used to monitor the impact of port construction on the local ecology, while changes in roads, buildings, and lights are used to monitor the economic impact. The results show that: (1)After nine years of expansion, the port area has gradually expanded from the central to the southern coastal area, with an increase of 21.68 hectares during the expansion period. After the expansion, the area of builidings and construction in the study area increased significantly, while the area of water and green areas decreased significantly, indicating that the port construction changed the land use structure of the area. (2) From the perspective of vegetation coverage, the vegetation coverage within $5 \mathrm{~km}$ from the port is in good condition. After 9 years, the vegetation coverage in the region between 0.6 and 1 increased from $43.71 \%$ to $44.25 \%$, reflecting the higher overall greening level in the region. (3) By analyzing the increase in roads and buildings, it can be seen that the port's comprehensive transportation capacity has improved, the population of the region has increased significantly. As the scale of construction has been continuously expanded, the 
35

prosperity as increased. (4) By analyzing the changes in the light index, the light data from the northeast to the southwest in the region is very obvious, and it is clearly located along the coast, indicating that the economic development of the coastal zone is faster than other regions, and the coastal region has promoted the development of the inland region.

\section{Introduction}

The "21st Century Maritime Silk Road" (MSR) is a major China-based initiative focused on domestic development, with benefits for international development throughout the region. The Port is a key component of the strategic infrastructure that supports the MSR transportation corridor. Additionally, port will attract new resources into area, and become an important node that will promote new opportunities for the country and strengthen international trade. Port development will increase gross domestic product, improve national income, provide more employment, and it plays an important role in regional and urban economic development. However, construction of infrastructure at the port has had profound impacts on regional land use. These impacts include ecological and environmental problems, such as erosion in the coastal zone and pollution and disturbance of the marine environment (Gupta et al., 2005; Peng et al 2014). Increases in maritime trade have driven an increase in the number of ports internationally, and remote sensing has been used to monitor and analyze the impacts of port construction on the regional ecology. Previous work has focused on the effects that the expansion of large and medium-sized ports have had on the temporal and spatial evolution of the natural environment. However, the number of small port expansions is increasing rapidly, so the impact of these smaller developments must also be investigated.

The methods used for port monitoring, and the results, are diverse. For example, Cowell and coworkers used measurements of the abundance of intertidal species near a dock in Valdez Port, Alaska, USA, to develop ecological for a rock bank baselines in the area (Cowell \& Monk, 1981). Gulbin and coworkers used a survey of benthic communities in Wrangel Bay, Peter Dam, Sea of Japan, to reveal the environmental impacts of port operations in the area (Gulbin et al., 2003). A three-stage SPOT image was used to study changes in land use in the vicinity of the lower reaches of the Thi Vai River in Ho Chi Minh City and Vung Tau City, southern Vietnam (Rutten et al., 2005). Smith and coworkers used baseline data that represented water quality, sediment quality, and benthic diversity to assess the ecological status of coastal resources in the Gulf of Mexico (Smith et al., 2007). Chen and coworkers used a combination of the comprehensive index method and the decision tree classification method to study changes in land used for construction in Qinzhou Port over an eight-year period (Chen \& Luo, 2009). Kidd explored the relationship between the historic public policy of Houston, Texas, and the development and expansion of the Houston port system and the impact of port expansion on the socioeconomic status of surrounding communities (Kidd, 2010). Portman and co-workers used parcel-level data and geographic information system (GIS) tools to study the interactions between fisheries and changing land use for two New England ports (Portman et al., 2011). Zhu and co-workers used a comprehensive analysis of land use in the coastal areas surrounding Bohai Bay to study the evolution of land use dynamics and spatial differentiation (Zhu et al., 2012). Liu and co-workers established four land use change index models, and used them to analyze the 
78

79

80

81

82

83

84

85

86

87

88

89

90

91

92

93

94

95

96

97

98

99

100

101

102

103

104

105

106

107

108

109

110

111

112

113

114

115

116

117

118

119

120

121

122

orientation and extent of spatial-temporal patterns and expansion patterns associated with changes in land use type in and around the Tianjin Port Area between 1987 and 2010 (Liu et al., 2012). Chen used remote sensing data to simulate the process of changing land use for the port cities of Dalian, China. The results were used to support decisions that promoted sustainable development in port cities (Chen \& Nuo, 2013). Bezerra and co-workers discussed the economic development of the Port of Pecém and Industrial Complex in Ceara, Brazil, and its impact on employment, environment, and health (Bezerra et al., 2014). Felsenstein and co-workers used microscopic simulation models and statistical estimates to determine the relationship between expansion of the Haifa Port and expected future land use (Felsenstein et al., 2014). Glory and coworkers used remote sensing and GIS to analyze the patterns and processes of changing land use around Port Harcourt, which is Nigeria's second largest port. These researchers monitored an increased rate of conversion from mangroves, wetlands, and water bodies to cultivated land, and a reduced rate of growth of the area of secondary vegetation and natural forests (Enaruvbe \& IgeOlumide, 2014). Liu used the normal cloud model to establish a comprehensive set of ecological indices for ports, and evaluated the ten largest Chinese ports, providing a basis for future port ecological development (Liu, 2014). Sany and co-workers developed biological indicators based on large benthic communities, and used the indicators to assess the ecological status of the marine environment (Sany et al., 2015). Zhao and Liu used the quantitative method of R clustering and coefficient of variation, combined with the qualitative method of expert experience, to study the 17 major ports such as Shanghai Port and Ningbo-Zhoushan Port, that proved the rationality of the ecological port evaluation index system. (Zhao \& Liu, 2015). Li and co-workers established a more detailed and applicable classification system, using multi-source and multi-resolution images to monitor and analyze land use changes in and around three typical ports in the vicinity of Xiamen Port (Li et al., 2016). Hassan and co-workers used remote sensing and GIS to monitor changes in land use and land cover in the southern part of the province that hosts Port Said in Egypt, and to assess the impact of the port on climate change (Hassan \& Omran, 2017). Huang and Liao used dynamic monitoring of remote sensing images and longterm observations to determine variation range at important ports in the Beibu Gulf. The results were combined with other data, including statistical data, to produce an analysis of the development of port construction and its impact on parameters such as terminal berths and cargo throughput (Huang \& Liao, 2017). Ge and co-workers used multi-temporal high spatial resolution remote sensing images to monitor infrastructure construction at the ports of Colombo and Hambantota between 2010 and 2017; the results were used to track the progress of the port construction, and to predict increases in annual port throughput through potential water storage (Ge et al., 2018). Li and co-workers used the five typical ports in the Bohai Sea as an example to establish a remote sensing monitoring technology process for the port space pattern, and constructed an index of various objects to quantitatively describe the port space composition and performance (Li et al., 2019). Zhong and co-workers constructed a mangrove wetland ecosystem health evaluation index based on Google Earth images, and explored the spatial and temporal differentiation of the health of the mangrove wetland ecosystem in the Zhangjiang Estuary, and the factors that influenced the wetlands (Zhong et al., 2019).

These previous studies have focused on the ecological and economic aspects of ports or coastal areas, including ecological aspects such as water quality, sediment quality, species diversity, cultivated land change, vegetation cover, mangrove status, wetland changes, and land use.

Peer) reviewing PDF | (2019:04:37164:2:1:NEW 16 Jul 2019) 
123 Economic aspects considered in the studies include rates of construction progress, construction

124 land use, level of industrial development, number of berths, port throughput, and public policies.

125 Research has generally focused on ecological or economic aspects; few remote sensing

126

127

128

129

130

131

132

133

134

135

136

137

138

139

140

141

142

143

144

145

146

147

148

149

150

151

152

153

154

155

156

157

158

159

160

161

162

163

monitoring analyses have focused on both. To address this, we use a comprehensive analysis of

remote sensing images to investigate ecological and economic consequences of the expansion of Ajmr Port, Davao City, in the Philippines.

The ecological environment is studied from the land. As a natural economic complex, land is not only an important part of the human-land system, but also the main space support for ecological civilization construction. Land use change is a core area of global environmental change and sustainable development research, affecting and changing the structure and function of the ecoeconomic system (Yu et al., 2010). In addition, we study ecology from the perspective of vegetation. As an important part of the ecosystem, vegetation has an important impact on the energy flow, material circulation and information transmission of surface ecosystems. Vegetation coverage can reflect the state and structure of vegetation growth and is an important indicator for climate change, soil erosion and hydrological processes. By monitoring land use change and vegetation coverage, we can understand the impact of port construction on the ecological environment of the area.

There are many indicators for social and economic development, such as roads, buildings, population, GDP, and per capita consumption levels. This paper selects three indicators for monitoring and analysis. The first indicator is the road, which is an important factor in the development of the regional economy. The radiation situation of road traffic reflects the radiation situation of the regional economy to a certain extent. The accessibility and convenience of the road have greatly promoted the development of the economy. The second indicator is building area, which is an important technical and economic indicator. In a certain period of the national economy, the completion of the construction area also marks the development of industrial and agricultural production in a country, the improvement of people's living and living conditions and the development of cultural and welfare facilities. The third indicator is the light index, which was first proposed by American scholars to point out that the brightness of a region' $\mathrm{s}$ night is proportional to its GDP. That is, the higher the light index value and the greater the change, the higher the prosperity of the representative city and the faster the economic development. By monitoring road changes, building area changes and light indices in the area, the economic impact of port construction on the area can be reflected.

\section{Study Area and Data Processing}

\section{Study area}

Ajmr Port located in the northern part of Davao City, Philippines, $15 \mathrm{~km}$ from Davao City. The city of Davao is located on the land about $946 \mathrm{~km}$ southeast of Manila(Figure 1). The city covers a total area of 2,443.61 square kilometers and is the largest city in the Philippines and the third most populous metropolitan area in the Philippines.There are several corporate terminals along

Peer] reviewing PDF | (2019:04:37164:2:1:NEW 16 Jul 2019) 
164 the coast of Davao City, including Texaco, Legazpi, National Warehouse, and the Philippines

165 Shell Oil Terminal.

166

167

168

Ajmr Port is mainly used to import and export goods for the Sumifru Company, so it is also

169 known as Sumifru Port and is part of the Philippines commercial port system. The Sumifru Company is a large-scale international enterprise that integrates planting, research and development, and import and export of tropical fruit products, including pineapple, banana, and

171 mango, with banana production accounting for three-quarters of the company's total fruit

172

173 cultivation. Davao has a tropical rainforest climate with little seasonal variation in temperature. Thus, the monthly average temperature is always relatively high with an average monthly rainfall

174

175 of over $77 \mathrm{~mm}$. The country's bananas are abundant in the mountains at elevations above $600 \mathrm{~m}$. The Sumifru Company currently has 12,010 hectares of banana plantations in five different regions of Davao City, Philippines. The total output and export volume of bananas ranks second among the Philippines-related industries, and its fruits are exported to China, Japan, South Korea, Iran and many other countries.

179

180

\section{Image data and pre-processing}

181

182

183

184

185

186

187

188

189

190

191

192

193

194

195

196

197

198

199

200

201

202

High-definition images that record the early stages of port construction are available from 2008, 2009, 2010, and 2012. This paper describes the process of the expansion of Ajmr Port. The highdefinition images show that the port of Ajmr changed significantly in 2012, indicating that the port began to expand after 2010. Images from 2009 to 2018 were selected for analysis (Figure 2).

Landsat images of the port taken between 2009 and 2018 were selected to monitor the vegetation cover before and after the port expansion. Images from Landsat7 and Landsat 8 were downloaded for 2009 and 2018, respectively. However, as a result of the failure of a Landsat 7 sensor in 2003, a large number of bands appeared in the image. These artefacts were repaired using the Landsat_gapfilter.sav plug-in, and by pre-treating the images in ENVI; processing included geometric corrections, image clipping, and atmospheric and radiation corrections. A square image centered on the port, with a side length of five kilometers, was obtained after the correction.

High-definition images were selected for the port area from 2009 to 2018 and used to classify the land use. The expansion lasted for nine years, and changes were continuous throughout this period. Monitoring for the present study, used images taken at three-year intervals, with images from 2009, 2012, 2015, and 2018. These high-resolution images were obtained from Google Earth; resolution is 1 meter. The images were corrected using the ENVI software so that the sample points were evenly distributed throughout the image, and the images were registered using the image to map method. The corrected images are amenable to dynamic change analysis. 
204

205

206

207

208

209

210

211

212

213

214

215

216

217

218

219

220

221

222

223

224

225

226

227

228

229

230

231

\section{2}

233

234

235

236

Time-series nighttime images from 2009 to 2018 were downloaded. Processing of the lighting images required extensive observation of the surrounding areas of the port, so the region of interest used for the study of night light data was a $40 \mathrm{~km} \times 40 \mathrm{~km}$, centered on the port. The night lighting data from 2009 to 2013 was taken from DMSP/OLS (operational line scanning system of the Defense Meteorological Satellite Program) and from VIIRS/DNB (visible infrared imaging radiometer kit day/night band) for 2013 to 2018. Compared with the OLS data, the VIIRS benefits from a finer space-time resolution, better data comparability between different years, and no data saturation. The acquisition of data from two different observation platforms using multiple sensors means that the downloaded images have to be pre-processed (Zou et al., 2014; Shi et al., 2014; Cao et al., 2015; Zhang et al., 2017; Wu et al., 2018). First, the images were cropped so they covered the same area. Then, the image was re-sampled so that all images had the same spatial resolution. A quadratic regression model was established to correct for differences between the sensors.

$$
D N_{\mathrm{c}}=\mathrm{a} \times D N^{2}+\mathrm{b} \times D N+\mathrm{c},
$$

where $\mathrm{DN}$ and $\mathrm{DN}_{\mathrm{C}}$ are the grayscale values before and after correction, and $\mathrm{a}, \mathrm{b}$, and c are regression parameters. Then, the DN values of the two sensor stable bright value pixel images in the same year are corrected.

$$
D N_{(\mathrm{n}, i) \_c}=\frac{D N_{(n, i)}^{\alpha}+D N_{(n, i)}^{\beta}}{2},
$$

where $D N_{(n, i)}^{\alpha}$ and $D N_{(n, i)}^{\beta}$ are the uncorrected $\mathrm{DN}$ values of pixel i acquired by sensors $\alpha$ and $\beta$ for year $\mathrm{n}$, and $D N_{(\mathrm{n}, \mathrm{i}) \_c}$ is the corrected $\mathrm{DN}$ value of pixel $\mathrm{i}$ in year $\mathrm{n}$. Finally, the DN value correction of the multi-sensor multi-year bright value pixel image is performed according to the change rule of the night light image. In cases where the DN value of a pixel in the DMSP/OLS light image for a particular year was less than the DN value for that pixel in the previous year, then the DN value should be corrected.

$$
D N_{(n, i)}=\left\{\begin{array}{l}
D N_{(n-1, i)}, D N_{(n-1, i)}>D N_{(n, i)} \\
D N_{(n, i)}, \text { others }
\end{array},\right.
$$

where $D N_{(\mathrm{n}-1, \mathrm{i})}$ and $D N_{(n, i)}$ represent the DN values of pixel i on the DMSP/OLS nighttime light image in years n-1 and n, respectively.

\section{Methods}

The Google Earth High Definition images were used to produce maps of the type of land use and to establish the timing of changes in land use. The Landsat images were used to create vegetation coverage maps and processed to assess changes in vegetation growth during port expansion; these data were used to monitor the ecological environment. The Google Earth High Definition

Peer] reviewing PDF | (2019:04:37164:2:1:NEW 16 Jul 2019) 
237

238

239

240

241

242

243

244

245

246

247

248

249

250

251

252

253

254

255

256

257

258

259

260

261

262

263

264

265

266

267

268

269

270

271

images were used to monitor the progress of port roads and building construction, and measure the density of port transportation infrastructure and housing density. These data were combined with the light images to calculate the annual brightness value of the port, plot the rate of change of light around the port, and to analyze the impact of small port construction on the local economy.

\section{Port ecological environment remote sensing monitoring analysis}

\section{Land use monitoring}

After pre-processing of the 2009, 2012, 2015, and 2018 high-resolution images from Ajmr Port, visual interpretation was used to analyze spatio-temporal dynamic changes. The scheme for the port classified features as roads, buildings, water, pier, container yard, bare land, other facilities, green areas, residential areas, or construction areas. The roads were classified as dirt roads, cement roads, or internal roads, and the area where the port is located was marked. The criteria used to classify the interpreted features are provided (Table $1 \&$ Figure 3).

The 2009 image was interpreted first. The interpreted image was compared with the next image (2012), and modified to create the 2012 land use map. The land use maps for 2015 and 2018 were derived in an analogous manner. Changes in the land use related to construction were determined by comparing the images.

\section{Vegetation growth sequence monitoring}

The normalized difference vegetation index (NDVI) for 2009 was calculated, based on the 2009 pre-processed Landsat imagery, and used to estimate the fractional vegetation cover (VFC) in the Ajmr Port region. First, the NDVI of the Landsat remote sensing image in 2009 was calculated, and then the maximum NDVI of the year was synthesized. Based on this image, the VFC was calculated using empirical equations.

$$
N D V I=\left(P_{n i r}-P_{r e d}\right) /\left(P_{n i r}+P_{r e d}\right)
$$

where $P_{\text {nir }}$ is the reflectance of the near-infrared band and $P_{\text {red }}$ is the reflectance of the red band, and

$$
V F C=\left(N D V I-N D V I_{\min }\right) /\left(N D V I_{\max }-N D V I_{\min }\right)
$$

where $\mathrm{NDVI}_{\max }$ and $\mathrm{NDVI}_{\text {min }}$ are the maximum and minimum NDVI values in the region, respectively.

To account for the inevitable noise in the images, $\mathrm{NDVI}_{\max }$ was set to the $95^{\text {th }}$ percentile of the DN data, and $\mathrm{NDVI}_{\text {min }}$ was set to the $5^{\text {th }}$ percentile of the DN data; this strategy minimized noise- 
272 related artefacts in the image. The same approach was used for the 2018 vegetation cover map. A 273 comparison of the two images was used to determine changes in vegetation cover before and 274 after port construction.

275

\section{Social and economic remote sensing monitoring analysis}

\section{Comparison changes in roads and buildings}

278

279

280

281

282

283

284

285

286

287

288

289

290

291

292

293

294

295

296

297

298

299

300

301

302

303

304

305

306

307

Roads are an important factor in the development of a regional economy, and the volume of road traffic reflects the regional economy to some extent. The accessibility and convenience of roads promotes economic development (Wang, 2014; Li, 2014; Yuan, 2018). In this study, changes to the roads inside the port region were determined, and divided into three grades according to the road construction status: dirt, cement, and the roads within the port. The roads were extracted from the high-resolution images. A comparison of images taken before and after the expansion project enabled visualization of traffic changes in the area, the density of the road network, the estimated traffic volume, and the extent of development of the port city.

The economic prosperity of the area can be estimated using a comparison of buildings in the port area before and after port construction. The number of buildings was counted, and the data used to calculate the area occupied by buildings and visualize the progress of port construction.

\section{Analysis of light changes}

Nighttime light is an objective measure of the productivity and activity of human society (Dolores, 2013; Xu et al., 2015; Wang \& Huang, 2018; Li et al., 2018). The lighting data were used to study development and activity in the port area, using a comparison of the bright and dark regions in the images. There is a positive correlation between the intensity of lighting and socio-economic factors. This paper used nighttime lighting data from 2009 to 2018 to determine changes to lighting in the port area. Comparisons of the lighting data over the nine-year period were used to identify areas where light changed in the study area, and to infer changes in demographic and the status of economic development.

\section{Results and analysis}

\section{The status of land use in the study area}

It was not possible to conduct field verification of features measured in the older images, because of changes to the port in recent years. Instead, the high-precision 0.3-m-resolution highdefinition image was used to verify the accuracy and revise the results where necessary. The accuracy of the corrected data is better than $90 \%$, which is considered to be satisfactory for the purposes of the study. At the time of construction, the area covered by the port was 9.46 
308

309

310

311

312

313

314

315

316

317

318

319

320

321

322

323

324

325

326

327

328

329

330

331

332

333

334

335

336

\section{7}

338

339

340

341

342

343

344

345

346

347

hectares. The port expanded to 19.96 hectares in 2012, 26.95 hectares in 2015 , and 31.14 hectares in 2018 (Figure 4).

Maps of land use type for 2009, 2012, 2015, and 2018 were constructed (Figure 5). There were large changes in land use type in the study area during port construction. The area occupied by the port increased by a total of 21.68 hectares during the expansion period, mainly through the addition of land previously occupied by water. From 2009 to 2018, port expansion gradually shifted from the central to the southern coastal region, mainly at the expense of green space. The most obvious features that changed during the expansion period are the areas of buildings, construction, bare land, water, other facilities, container yards, roads, and green space. Among these, there was a significant increase in the area occupied by buildings, construction, bare land, other facilities, container yards, and roads, with increases of 10.05, 8.58, 5.1, 4.43, 8.68 and 4.06 hectares, respectively. These increases were accommodated by a reduction in area occupied by water and green space, with reductions of 12.02 and 29.95 hectares, respectively.

The areas of different land use types in the study area from 2009 to 2018 are shown in Table 2. There was significant expansion in the northern part of the port area in 2012, relative to 2009 (Figure 5A\& B). Green areas, bare land, and water in the 2009 image were built on and expanded to become container yards, construction areas, roads, and other facilities in the later images. The area of these construction-related land use types increased by 6.71 hectares. Between 2012 and 2015, a 104-m-long, 23-m-wide, pier and ship-landing infrastructure was added to the northern port region, and the southern parts of the port area expanded (Figure 5 B \& $C)$. A total of 2.57 hectares originally classified as green space and construction area was converted into port land, with an associated 9.6-hectare increase in the area classified as bare land. Between 2015 and 2018, the port produces 2.81 hectares of land through occupied waters, mostly in the eastern parts of the study area, to provide a container yard and construction area. The original construction area in the western part of the port was converted to buildings that covered an area of 3.79 hectares. Container yards increased by 5.42 hectares compared to 2015 .

\section{Monitoring of changes to vegetation coverage}

Five areas within the study area were randomly selected for accuracy verification using the 0.3m-resolution high-definition image. The accuracy calculated for the five sample areas in 2009 was $82.5 \%, 88.1 \%, 94.6 \%, 91.3 \%, 87.5 \%$, and the average accuracy was $88.8 \%$. The accuracy of the five sample areas in 2018 was $81.2 \% 86.4 \%, 93.5 \%, 92.7 \%$, and $87.2 \%$, with an average accuracy of $88.2 \%$ (Figure 6 ). These data were more than $80 \%$ accurate and meet the experimental requirements.

The fractional vegetation cover map of $5 \mathrm{~km}$ around the port was mapped (Figure 7). In 2009, the boundary between the water and the vegetation is clearly defined (Fig. 7A). Within this region, $11.34 \%$ of the vegetation ranged from 0.2 to $0.6,10.83 \%$ of vegetation ranged from 0.6 
348

349

350

351

352

353

354

355

356

357

358

359

360

361

362

363

364

365

366

367

368

369

370

371

372

373

374

375

376

377

\section{8}

379

380

381

382

383

384

385

386

387

to 0.8 , and $32.88 \%$ of the vegetation ranged from 0.8 to 1 . A total of $43.71 \%$ of the vegetation, which covered an area of $10.94 \mathrm{~km}^{2}$, was between 0.6 and 1 .

In $2018,14.62 \%$ of the vegetation ranged from 0.2 to $0.6,8.35 \%$ of the vegetation ranged from 0.6 to 0.8 , and $33.9 \%$ of the vegetation ranged from 0.8 to 1 (Fig. $7 B$ ). The proportion of the vegetation between 0.8 and 1 was higher in $2018(33.9 \%)$ than it was in $2009(32.88 \%)$. A total of $44.25 \%$ of the vegetation, which covered an area of $10.58 \mathrm{~km}^{2}$, was between 0.6 and 1 ; these values are similar to those calculated for 2009 (Table 3 ). Vegetation coverage is an important indicator of the quality of the ecological environment in a region (Alo \& Pontius, 2008; Xin et al., 2008; Amarsaikhan et al., 2009; Chen \& Wang, 2009; Zhang et al., 2010; Lu et al., 2017; Li et al., 2019). Thus, the comparison of the two images shows that the port expansion has not had a significant impact on the ecological status of the area, reflecting the higher overall greening level in the area.

\section{Analysis of changes in the port roads and buildings}

The accuracy of road and building data on the revised 0.3-m-resolution high-definition image is better than $90 \%$. During the nine-year expansion of the port, there were significant increases in the areas occupied by roads and buildings (Figure 8). Seven new roads covering an area of 2.97 hectares appeared in the port; the new roads were mainly concentrated in the northeastern part of the port. A large number of container areas were added on the newly reclaimed land, so the number of transportation pathways for goods increased accordingly.

Changes to buildings after the expansion included an increased number of buildings in the central and southern regions of the port. Expansion involved the addition of 22 new buildings with an area of 3.87 hectares. This large area of the port was converted at the expense of green space and water. The new roads and buildings accounted for $9.54 \%$ and $12.43 \%$ of the total area of the port, respectively, which is a relatively small proportion. The increase in the construction area reflects an increase in the population around the port, and the expansion of construction scale.

\section{Port Light Change Analysis}

The port is adjacent to Panabo City to the north and Davao City to the south. Davao City is the only independent city in the Davao District of Northern Mindanao and is the most populous city, while the city of Panabo is a small city in the north of Davao. The time-series dynamic lighting monitoring of the $40 \mathrm{~km} \times 40 \mathrm{~km}$ area around the port of Ajmr provided lighting data from 2009 to 2018 (Figure 9). A comparison of the port lighting data with that of the adjacent cities showed that there was a significant increase in lighting at the port, especially in 2011 to 2015. During this time, the port's lighting data was close to that of Davao, so grew significantly. The nine-year lighting dataset from the cities of Panabo and Davao also showed increases in lighting, but the rate of growth was slower than at the port. 
389 Differences between the 2009 and 2018 lighting images were calculated to obtain the nine-year

390

391

392

393

394

395

396

397

398

399

400

401

402

403

404

405

406

407

408

409

410

411

412

413

414

415

416

417

418

419

420

421

422

423

424

425

426

427

428

429

lighting growth rate around the port (Figure 10). The expansion of lighting from the northeast to the southwest is clear, highlighted by the red curve. From the high-definition image, it can be seen that the red curve passes over the coast southeast of Mindanao in the southern Philippines. The rate of growth of lighting along the coastline was commonly between 100 to 150 , or greater. Panabo City and Davao City also had lighting growth rates between 100 and 150, and both are located on the coast. Before the expansion of Ajmr Port, the port's economic development level was low. However, after nine years of continuous expansion, the rate of economic development in the region increased, indicating that construction at the port promoted local economic development. Ajmr Port, Panabo City, and Davao City form an economic belt on the southeast coast of Mindanao, which has promoted economic development on the coast.

The lighting in large areas on the east side of the port grew at relatively low rates, between 0 and 50. The high-resolution images show that this slow-growth area is northwest of Davao Bay and Samal Island. The growth of lighting data in the sea areas is mainly due to ships. The large number of vessels in the water indicates the frequency of maritime transport trade in the region. The relevant data show that export volumes from Ajmr Port are large, and that there are numerous trading partners (Ahmad \& Chua, 2013; Dhang \& Partho, 2015; Zhai et al., 2016). In 2015, the Sumifru Company began to export South American bananas to China. This company relies on China's Dalian, Tianjin, Shanghai, Shenzhen, and other coastal ports for trade. It has established large processing, storage, and sales organizations in the major port cities of China that provide fresh fruit to the Chinese mainland. Relationships between China and the Philippines have benefited from this "21st Century Maritime Silk Road" (Zhai et al., 2016). Through the continuous increase in sea-based trade, China has become the largest export market for bananas from the Philippines.

\section{Conclusions}

After nine years of expansion, the port area has gradually expanded from the central to the southern coastal area, with an increase of 21.68 hectares during the expansion period.After the expansion, the area of builidings and construction in the study area increased significantly, while the area of water and green areas decreased significantly, indicating that the port construction changed the land use structure of the area. From the perspective of vegetation coverage, the vegetation coverage within $5 \mathrm{~km}$ from the port is in good condition. After 9 years, the vegetation coverage in the region between 0.6 and 1 increased from $43.71 \%$ to $44.25 \%$, reflecting the higher overall greening level in the region.

After 9 years of expansion, there are 7 new roads in the northeastern part of the port, covering an area of 2.97 hectares. There are 22 new buildings in the central and southern ports, occupying an area of 3.87 hectares that is relatively large. By analyzing the increase in roads and buildings, it can be seen that the port's comprehensive transportation capacity has improved, the population of the region has increased significantly. As the scale of construction has been continuously

Peer] reviewing PDF | (2019:04:37164:2:1:NEW 16 Jul 2019) 
430 expanded, the prosperity as increased. By analyzing the changes in the light index, the light data 431 from the northeast to the southwest in the region is very obvious, and it is clearly located along 432 the coast, indicating that the economic development of the coastal zone is faster than other 433 regions, and the coastal region has promoted the development of the inland region.

\section{Discussion}

The research that had been carried out was a unilateral study of the port. This paper has carried out remote sensing monitoring and analysis of the five aspects of economic development and ecological environment from the port of Ajmr in the Philippines from 2009 to 2018, which fills the gap in the comprehensive study of port construction monitoring. The small ports were monitored and analyzed, which was different from the traditional large port monitoring. It is found that the same problem exists in the construction of small ports - the problem between port construction and environmental protection.

This paper carries out monitoring and analysis from two aspects of ecological environment and economic development. The ecological environment refers to the general name of the quantity and quality of water resources, land resources, biological resources and climate resources that affect human survival and development, and is a complex ecosystem related to the sustainable development of society and economy. Because the ecological environment includes a wide range, research is not possible in every aspect. The research content of this paper monitors the ecological status of the area from two aspects. Remote sensing monitoring and analysis can also be carried out from the aspects of water resources and ecological resources. For example, Lisa M. Smith et al. used water quality, sediment quality, and benthic diversity data as baselines to assess the ecological status of coastal resources in the Gulf of Mexico (Smith et al., 2007). Cowell E B et al. conducted a monitoring survey of the abundance of intertidal species near the dock at Valdez Port, Alaska (Cowell \& Monk, 1981).

The economy also includes many indicators, such as population, GDP, employment status, public policy and other statistics. This paper monitors and analyzes road and building changes and lighting growth. If you add some social and economic indicators to supplement, and use more targeted statistical analysis methods, you can get richer analysis results. For example, Kidd M A explores the impact of historical public policy and port expansion in Houston, Texas on the socioeconomic status of surrounding communities (Kidd, 2010). index method, decision tree classification method, microscopic simulation model, and land use 
469 change index model. The method of establishing the model can be used for reference and can

470 improve the accuracy of the prediction.

471

472 Based on the above research and analysis, the contradiction between the economic development 473 of the port area and the local environmental protection still exists. How to reduce environmental 474 damage and build an ecological port is still a focus of attention. This paper believes that: First, 475 the environment can be protected by rational planning of land during the construction process. 476 And when occupying green space, it should add a green space in other places to keep the overall 477 478

479

480 green area unchanged. Secondly, the environment can also be protected by improving the equipment inside the port, for example, using environmentally clean materials for loading and unloading goods and construction. Finally, effective degradation and treatment of wastewater and waste gas from port removal are also important measures to protect the environment.

481

482

\section{Acknowledgements}

483

484

485

486

487

488

489

490

491

492

493

494

495

496

497

498

499

500

501

502

503
The author is grateful to the State Key Laboratory of Remote Sensing Science of the Institute of Remote Sensing and Digital Earth of the Chinese Academy of Sciences for providing the data needed for this article. The author expresses her thanks to Professor $\mathrm{Wu}$ for his support, encouragement, and comments on a previous version of the paper. The author also expresses thanks for the methodological guidance given by Mr. Tian.

\section{References}

Gupta A K, Gupta S K, Patil R S. 2005. Environmental management plan for port and harbour projects. Clean technologies and environmental policy 7(2):133-141.

DOI:10.1007/s10098-004-0266-7

Peng S, Qi X, Zhou R, Wang X, Shi H. 2014. Ecological Risk Assessment of Bohai Bay Port. Chinese Journal of Ecology 34(1): 224-230. (In Chinese)

Cowell E B, Monk D C.1981. Problems in ecological monitoring in Port Valdez, Alaska. Proceedings of the Royal Society of Edinburgh. Section B. Biological Sciences 80:355-366. DOI:10.1017/s0269727000006655

Gulbin V V, Arzamastsev I S, Shulkin V M. 2003.Ecological Monitoring of the Water Area of Port Vostochnyi (Wrangel Bay) in the Sea of Japan (1995-2002). Russian Journal of Marine Biology 29(5):284-295. DOI:10.1023/a:1026305410235

Peer) reviewing PDF | (2019:04:37164:2:1:NEW 16 Jul 2019) 
504

505 Rutten C, Binh D K N T, Hens L. 2005. Land cover changes in SEA of port development in

506

507

508

509

510

511

512

513

514

515

516

517

518

519

520

521

522

523

524

525

526

527

528

529

530

531

532

533

534

535

536

537

538 the Vung Tau area (South Vietnam). International experience and perspectives in SEA location:Prague date:26-30 September 2005.

DOI:https://lirias.kuleuven.be/handle/123456789/218325

\section{Smith L M, Didonato E M, Harwell L C, Nestlerode J A, Summers K. 2007. The} ecological condition of Gulf of Mexico resources from Perdido Key to Port St. Joe, Florida: Part II near-shelf coastal resources. Environmental Monitoring and Assessment 127(1-3):189207.DOI:10.1007/s10661-006-9273-y

Chen Y, Luo Y. 2009. Dynamic Monitoring on land use Change of port Based on TM and ETM + Data. Journal of Meteorological Research and Application 30(03):60-62+67+118 (in Chinese)

Kidd M A. 2010. Port of Houston impact on the socio-economic status of surrounding neighborhoods: A case study in Houston, Texas. International Conference on Geoinformatics. IEEE. DOI:10.1109/GEOINFORMATICS.2010.5567486

Portman M E , Jin D , Thunberg E. 2011 The connection between fisheries resources and spatial land use change: The case of two New England fish ports. Land Use Policy 28(3):0-533. DOI:10.1016/j.landusepol.2010.10.007

Zhu G , Xu X , Ma Z , Xu L, Porter J H. 2012.Spatial Dynamics and Zoning of Coastal Land-Use Change along Bohai Bay, China, during 1979-2008. Journal of Coastal Research 284(5):1186-1196. DOI:10.2112/jcoastres-d-11-00139.1

Liu B, Huang Y, Fu J, Jiang D. 2012. Analysis of Temporal and Spatial Pattern Changes and Driving Forces of Land Use in Tianjin Port Area. Journal of Geographic Information Science 14(2): 270-278. (In Chinese)

Chen L, Nuo W. 2013. Dynamic Simulation of Land Use Changes in Port City: A Case Study of Dalian, China. Procedia - Social and Behavioral Sciences 96, 981-992.

DOI:10.1016/j.sbspro.2013.08.112 
539 Bezerra M D G V, Rigotto R M, Pessoa V M ,Da Silva F U E. 2014. The implications of 540 economic development on work, the environment and health in port communities in the State of 541 Ceará, Brazil. Ciência \& Saúde Coletiva 19(10):4023-30. DOI:10.1590/1413-

$542 \quad 812320141910.09802014$

543

544 Felsenstein D , Lichter M , Ashbel E. 2014. Coastal congestion: Simulating port expansion 545 and land use change under zero-sum conditions. Ocean \& Coastal Management 101:89-101.

546 DOI:10.1016/j.ocecoaman.2014.08.001

547

548 Enaruvbe G O, Ige-Olumide O. 2014. Geospatial analysis of land- use change processes in a 549

550 densely populated coastal city: The case of Port Harcourt, south- east Nigeria. Geocarto International 30(4):441-456. DOI:10.1080/10106049.2014.883435

551

552

Liu F. 2014. Ecological port evaluation based on normal cloud model. Modern Business 3(1) :

553 201-203. (In Chinese)

554

555

Sany S B T, Hashim R, Salleh A, Rezayi M, Safari O. 2015.Ecological quality

556

557

558

559 assessment based on macrobenthic assemblages indices along West Port, Malaysia coast. Environmental Earth Sciences 74(2):1331-1341.DOI:10.1007/s12665-015-4122-3

559

Zhao Y, Liu F. 2015. The construction of ecological port index system:Based on R clustering, coefficient of variation and expert experience analysis. Research Management 2(2): 124-132. (In

561 Chinese)

562

563

564

Li J, Bai L, Li J, Nie Y, Yang P, Qin J, Qu R. 2016. Monitoring and analysis of land use change in Xiamen Harbor area based on multi-source remote sensing images. 2016 IEEE

565 International Geoscience and Remote Sensing Symposium (IGARSS).

566 DOI:10.1109/igarss.2016.7730905

567

568

Hassan M A E R, Omran E S E. 2017. Modelling of land-use changes and their effects by

569 climate change at the southern region of Port Said governorate, Egypt. Modeling Earth Systems

570 \& Environment 3(1):13.DOI:10.1007/s40808-017-0276-1

571

572 Huang P, Liao Y. 2017. Dynamic Monitoring of Remote Sensing Image in Beibu Gulf Port 573 Construction. Geospatial Information 15(03): 20-22+10. (In Chinese) 
574

575 Ge Y, Chen Y, Jia Y, Guo X, Hu S. 2018. Dynamic monitoring the infrastructure of major 576

577 ports in Sri Lanka by using multi-temporal high spatial resolution remote sensing images.

Journal of Geographical Sciences 28(07) :973-984. DOI:10.1007/s11442-018-1516-7

578

Li X, Xu H, Su A. 2019. Monitoring and Evaluation of Intensive Use in Port Area Based on High Spatial Resolution Remote Sensing Image:Taking Five Typical Port Areas of Bohai as an

581 Example.Applied Ocean University 38(01):126-134. (In Chinese)

582

583

584

585

586

587

588

589

590

591

592

593

594

595

596

597

598

599

600

601

602

603

604

605

Zhong L, Lu C, Wang Z, Liu M, Chen Y, Lin X, Su Y, Jia M. 2019. Health Assessment of Mangrove Wetland Ecosystem in Minjiang Estuary Based on GIS and RS. Journal of Ecology 113[2019 -06-05].https://doi.org/10.13292/j.1000-4890.201908.004.(In Chinese)

Yu M , Chen D , Huang R , Ai T. 2010. A dynamic analysis of regional land use and cover changing (LUCC) by remote sensing and GIS: taking Fuzhou area as example. Proceedings of SPIE - The International Society for Optical Engineering 7673:76730J-76730J-8. DOI:10.1117/12.852546

Zou J, Chen Y, Tian J, Wang T. 2014. Construction of DMSP/OLS Night Light Image Correction Model Based on ArcGIS. Geomatics of Surveying and Mapping 39(04): 33-37. (In Chinese)

Shi K, Huang C, Yu B, Yin B, Huang Y, Wu J. 2014. Evaluation of npp-viirs nighttime light composite data for extracting built-up urban areas. Remote Sensing Letters 5(4), 358366.DOI:10.1080/2150704X.2014.905728

Cao Z, Wu Z, Yan Y, Huang N. 2015. Correction and Application of DMSP/OLS Night Light Image in China. Journal of Geo-Information Science 17(09):1092-1102. (In Chinese)

Zhang M, He Z, Fan Y. 2017. Correction method of DMSP/OLS stable nighttime light image. Bulletin of Surveying and Mapping (12): 58-62+76. (In Chinese) 
606

607 Wu J, Li S, Zhang Y. 2018. Study on saturation correction of long-term nighttime remote 608 sensing data of Chinese DMSP-OLS. Journal of Remote Sensing 22(04):621-632. (In Chinese)

609

610 Wang D. 2014. Relationship between Regional Economic Sustainable Development and Road

611 Traffic Radiation. China Management Informationization 17(05):106. (In Chinese)

612

613 Li H. 2014. Relationship between Regional Economic Sustainable Development and Road

614 Traffic Radiation. Corporate Reform and Management (19):12-13 (In Chinese)

615

616 Yuan H. 2018. Discussion on the relationship between road transportation and urban economic 617 development.China Market (10):39+45. (In Chinese)

618

619 Dolores J F. 2013. Multi-scale analysis of the relationship between economic statistics and 620 DMSP-OLS night light images. Mapping Sciences \& Remote Sensing. 50(5):483-499.

621 DOI:10.1080/15481603.2013.823732

622

Xu H, Yang H, Li X, Jin H, Li D. 2015. Multi-Scale Measurement of Regional Inequality in

Density Grid Data.Sustainability 7,13469-13499. DOI:10.3390/su71013469

626

627

Wang X, Huang L. 2018. Nighttime Light Data and Its Application in Economic Research.

628

Economics (10): 75-87. (In Chinese)

629

630

Li X, Zhao L, Han W, Bouarouri F, Prosper W, Zhang X, Jin H, Wu C. 2018.

631

Evaluating Algeria' s social and economic development using a series of nighttime light images

632 between 1992 to 2012. International Journal of Remote Sensing 1-21.

633 DOI:10.1080/01431161.2018.1510560

634

Alo C A, Pontius R G. 2008. Identifying Systematic Land-Cover Transitions Using Remote 636 
639

640

641 Xin Z, Xu J, Zheng W. 2008. Spatiotemporal variations of vegetation cover on the chinese 642 loess plateau (1981-2006): impacts of climate changes and human activities. Science in China

643 Series D: Earth Sciences 51(1), 67-78. DOI:10.1007/s11430-007-0137-2

644

645

Amarsaikhan D, Blotevogel H H, Ganzorig M, Moon T-H. 2009. Applications of remote

646 sensing and geographic information systems for urban land-cover change studies in

647 Mongolia.Geocarto International 24:257-271. DOI:10.1080/10106040802556173

648

649

Chen X, Wang H. 2009. Temporal and spatial changes of vegetation cover and vegetation

650 coverage in Inner Mongolia from 1982 to 2003. Journal of Geographical Sciences 64(1): 84-94.

651 (In Chinese)

652

Zhang T, Zhang J, Shen Y, Duo F.2010. Analysis of vegetation variation characteristics in

654 Northwest China from 1981 to 2001. Chinese Agricultural Meteorology 31(4): 586-590. (In 655 Chinese)

656

Lu G, Han M, Wang M, Zhu L, Li H. 2017. Temporal and spatial variation of vegetation coverage in the modern Yellow River Delta. Journal of Eco-Environment 26(3): 422-428. (In 659 Chinese)

660

Li W, Song X, Liu W, Chen H. 2019. Study on the Temporal and Spatial Changes of Vegetation Coverage in Dalian. Journal of Liaoning Normal University(Natural Science Edition) 663 42(01):93-98. (In Chinese)

664

Zhai H, Tang H, Zhang F. 2016. The current situation of fruit production and trade in the Philippines and the prospect of fruit trade in China and the Philippines. Statistical analysis of fruit production and trade in major countries along the Belt and Road Initiative (6).China Fruit 668 Industry Information 33(11): 13-28. (In Chinese)

669

670

Ahmad I, Chua P C. 2013. TRENDS IN PRODUCTION AND TRADE OF TROPICAL

671 FRUITS IN ASEAN COUNTRIES. Acta horticulturae, (975):559-580.

672 DOI:10.17660/ActaHortic.2013.975.73 
673

674 Dhang, Partho. 2015. Mango Pulp Weevil (Sternochetus Frigidus): an Invasive Species with 675 Economic Significance in the Philippines. Outlooks on Pest Management, 26(4):157-159.

676 DOI:10.1564/v26_aug_04

677 


\section{Table $\mathbf{1}$ (on next page)}

Local object identification and judgment methods 
Road

Waters

Container yard

Bare land

Other facilities

Green space

Residential area

Construction area
Dirt road: the color is grayish white, the road is thinner and the shape is irregular (Fig.3A); the cement road: the color is grayish black, the road is straight and very wide (Fig.3B); roads within the port: the color is gray, long Strips, wide roads, located in the inner area of the port (Fig.3C)

The colors are white, dark green, blue, etc., the shape is a regular polygon, the area is large, and there are generally roads around (Fig.3D)

The color is dark green, which is a large area, and there are a small amount of sandstone and silt accumulation in the coastal area (Fig.3E).

The color is gray, and the shape is a regular rectangle. In the coastal area, there are ships nearby, and there are generally goods and vehicles on the dock (Fig.3F).

The colors of the containers are different, the shape of the yard is relatively regular, and there are many roads and containers inside (Fig.3G).

The general color is brown, the shape is irregular, and there is no vegetation, construction and construction facilities inside (Fig. $3 \mathrm{H}$ )

The color is dark blue or dark gray, and the area is relatively regular, generally for various mechanical equipment or workshops (Fig.3I)

The color is green, it is a flaky area, and there are various trees, grasses and other vegetation inside (Fig.3J)

The color is mostly red and blue, and the flaky area is irregular. There are roads and a small number of trees inside (Fig.3K)

The color is grayish white, irregular, with obvious construction traces or construction equipment (Fig.3L) 
Table 2 (on next page)

Area of various types of features in the study area (hectare) 


\begin{tabular}{|c|c|c|c|c|}
\hline $\begin{array}{l}\text { Feature } \\
\text { category }\end{array}$ & August 2009 & August 2012 & July 2015 & July 2018 \\
\hline Building & 6.87 & 9.37 & 12.21 & 16.92 \\
\hline Waters & 118.53 & 112.55 & 109.28 & 106.51 \\
\hline Pier & 1.27 & 1.27 & 1.57 & 1.57 \\
\hline Bare land & 8.07 & 6.42 & 14.61 & 13.17 \\
\hline Road & 6.65 & 7.65 & 9.12 & 10.71 \\
\hline Green space & 87.3 & 78.34 & 66.59 & 57.35 \\
\hline $\begin{array}{c}\text { Construction } \\
\text { area }\end{array}$ & 1.27 & 7.98 & 10.01 & 9.85 \\
\hline $\begin{array}{c}\text { Residential } \\
\text { area }\end{array}$ & 23.02 & 23.23 & 23.23 & 23.79 \\
\hline $\begin{array}{c}\text { Other } \\
\text { facilities }\end{array}$ & 3.22 & 6.29 & 6.32 & 7.65 \\
\hline $\begin{array}{c}\text { Container } \\
\text { yard }\end{array}$ & 2.23 & 5.33 & 5.49 & 10.91 \\
\hline
\end{tabular}




\section{Table 3 (on next page)}

Statistics of vegetation coverage around the port of Ajmr in 2009 and 2018 


\begin{tabular}{ccccccccc}
\hline Years & $\begin{array}{c}\text { Vegetation } \\
\text { coverage }\end{array}$ & $\mathbf{0 - 0 . 2}$ & $\mathbf{0 . 2 - 0 . 4}$ & $\mathbf{0 . 4 - 0 . 6}$ & $\mathbf{0 . 6 - 0 . 8}$ & $\mathbf{0 . 8 - 0 . 9}$ & $\mathbf{0 . 9 - 1}$ & Total \\
\hline & $\begin{array}{c}\text { area }\left(\mathrm{km}^{2}\right) \\
2009\end{array}$ & 11.25 & 1.25 & 1.59 & 2.71 & 3.52 & 4.71 & 25.03 \\
& $\begin{array}{c}\text { Proportion } \\
(\%)\end{array}$ & 44.95 & 4.99 & 6.35 & 10.83 & 14.06 & 18.82 & 100.00 \\
& & & & & & & & \\
& $\begin{array}{c}\text { area }\left(\mathrm{km}^{2}\right) \\
2018\end{array}$ & 10.8 & 2.05 & 1.61 & 2.09 & 2.38 & 6.11 & 25.04 \\
& $\begin{array}{c}\text { Proportion } \\
(\%)\end{array}$ & 43.13 & 8.19 & 6.43 & 8.35 & 9.50 & 24.40 & 100.00 \\
& & & & & & & & \\
\hline
\end{tabular}

1 
Figure 1

Research area location

@ 2018 Google Earth 

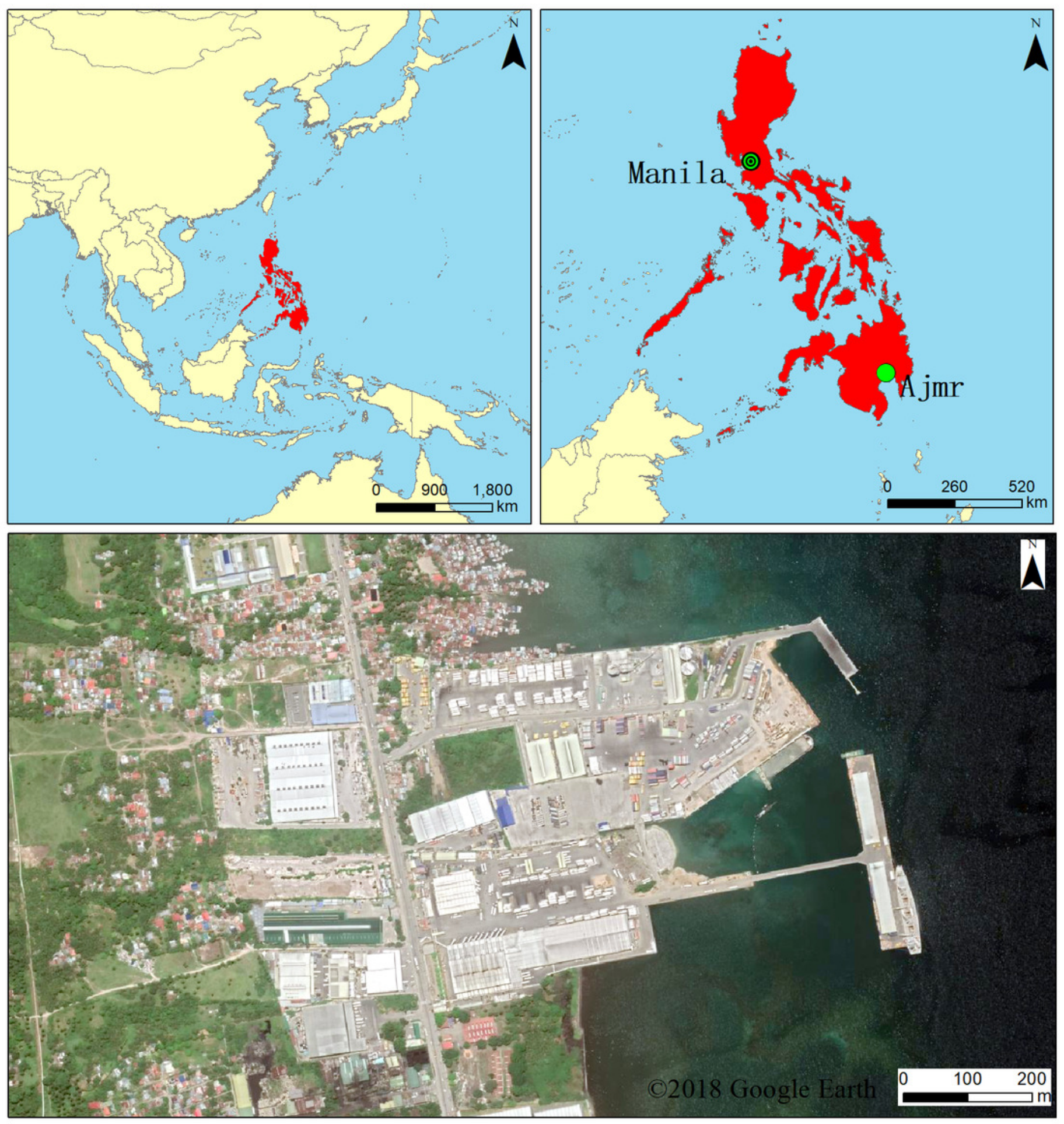

$\begin{array}{lll}\text { Legend } & \text { () } & \text { Capital } \\ \bigcirc & \text { Port location }\end{array}$

The Philippines

Ocean

0ther countries 
Figure 2

High-definition images of the 2008(A), 2009(B), 2010(C) and 2012(D) in study areas

A: @2008 Google Earth, B: @2009 Google Earth, C: @2010 Google Earth, D: @2012 Google Earth
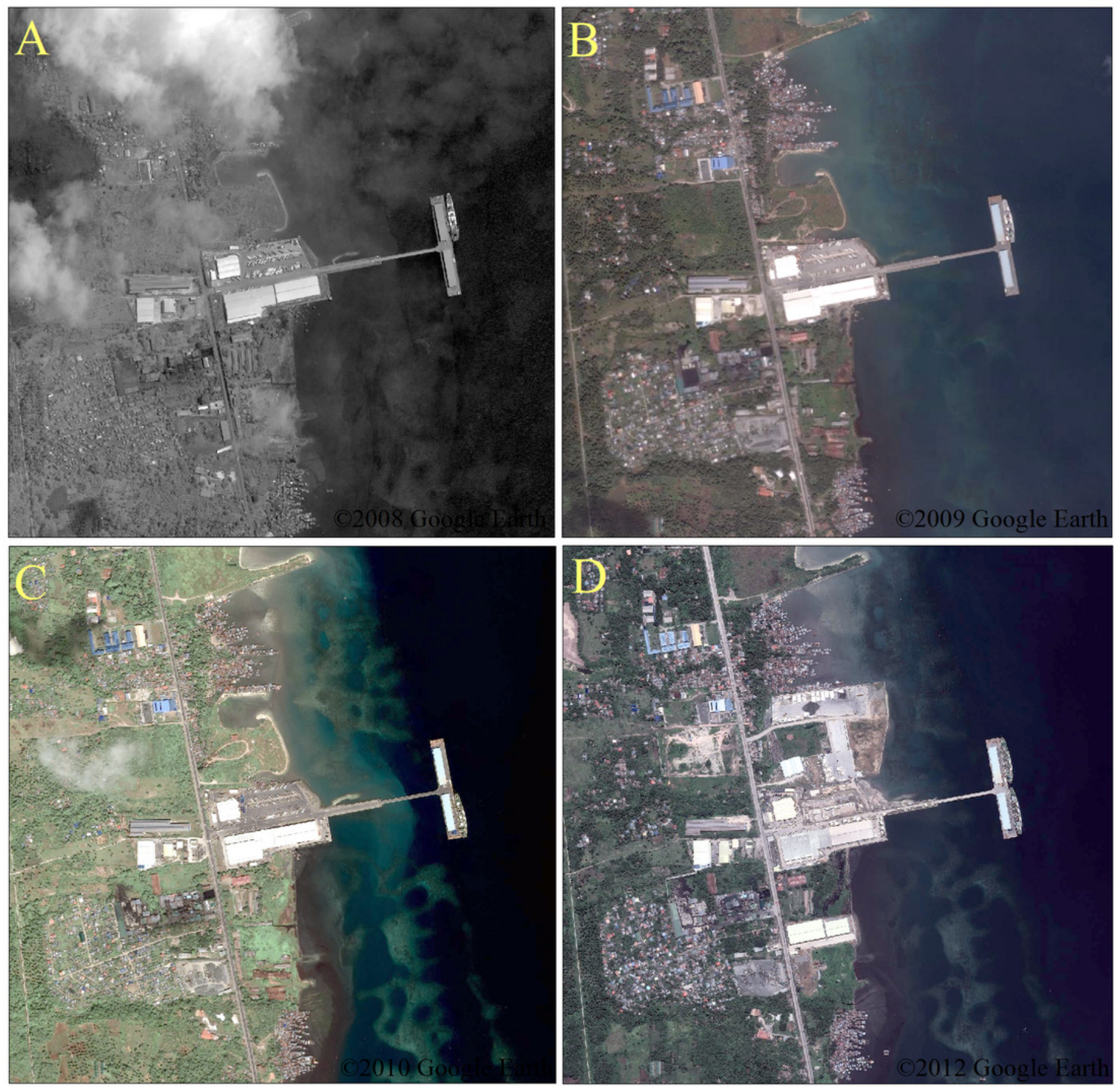
Figure 3

\section{Visual interpretation of various feature}

(A) dirt road, (B) cement road, (C) roads within the port, (D) building, (E) waters, (F) pier, (G) container yard,

$(\mathrm{H})$ bare land, $(\mathrm{I})$ other facilities, $(\mathrm{G})$ green space, $(\mathrm{K})$ residential area, $(\mathrm{L})$ construction area

A-F: @2 2015 Google Earth, G-L: @2016 Google Earth
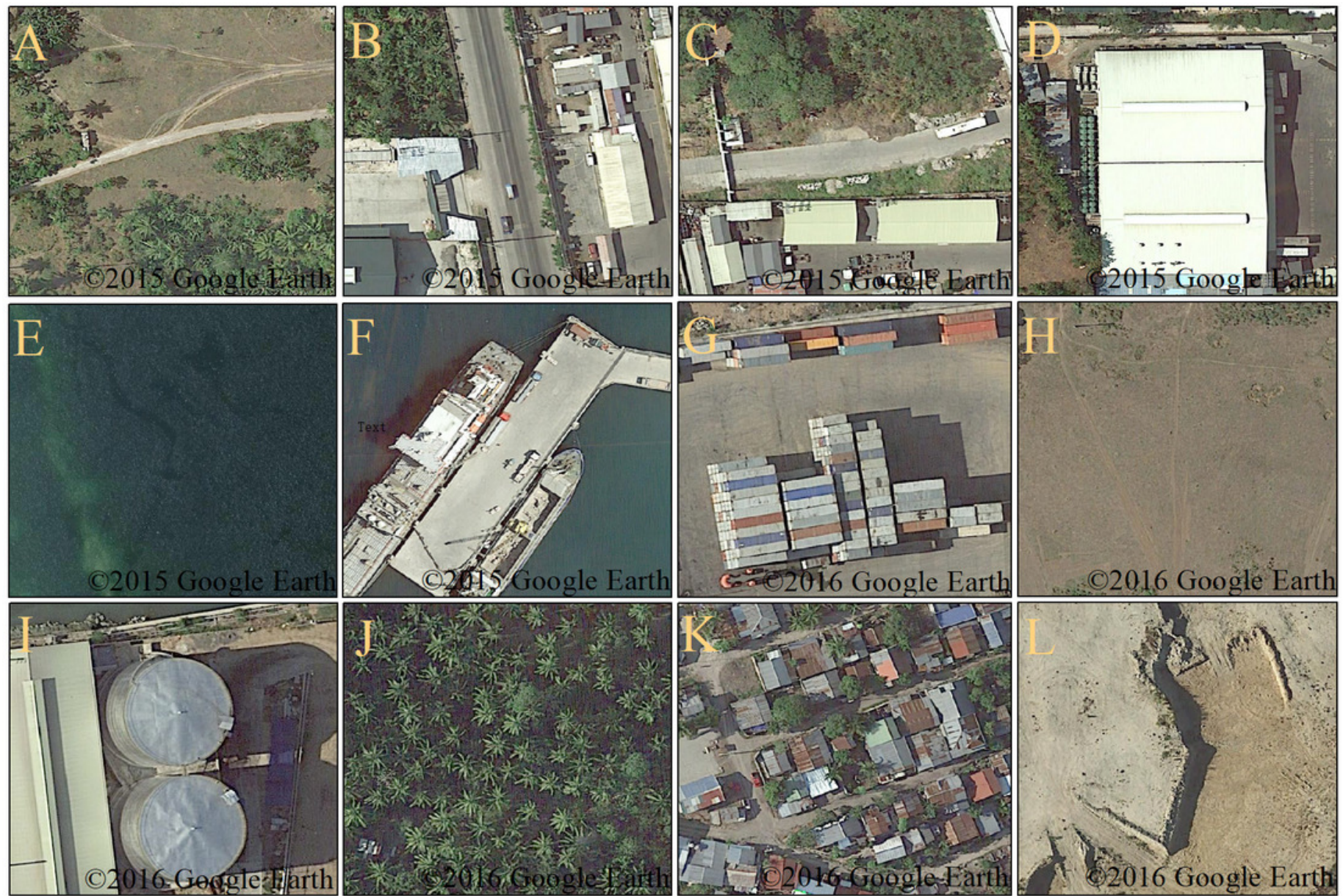
Figure 4

Port expansion chart of the 2009(A), 2012(B), 2015(C) and 2018(D)

A: ๑2009 Google Earth, B: ๑2012 Google Earth, C: ๑2015 Google Earth, D: ๑2018 Google Earth
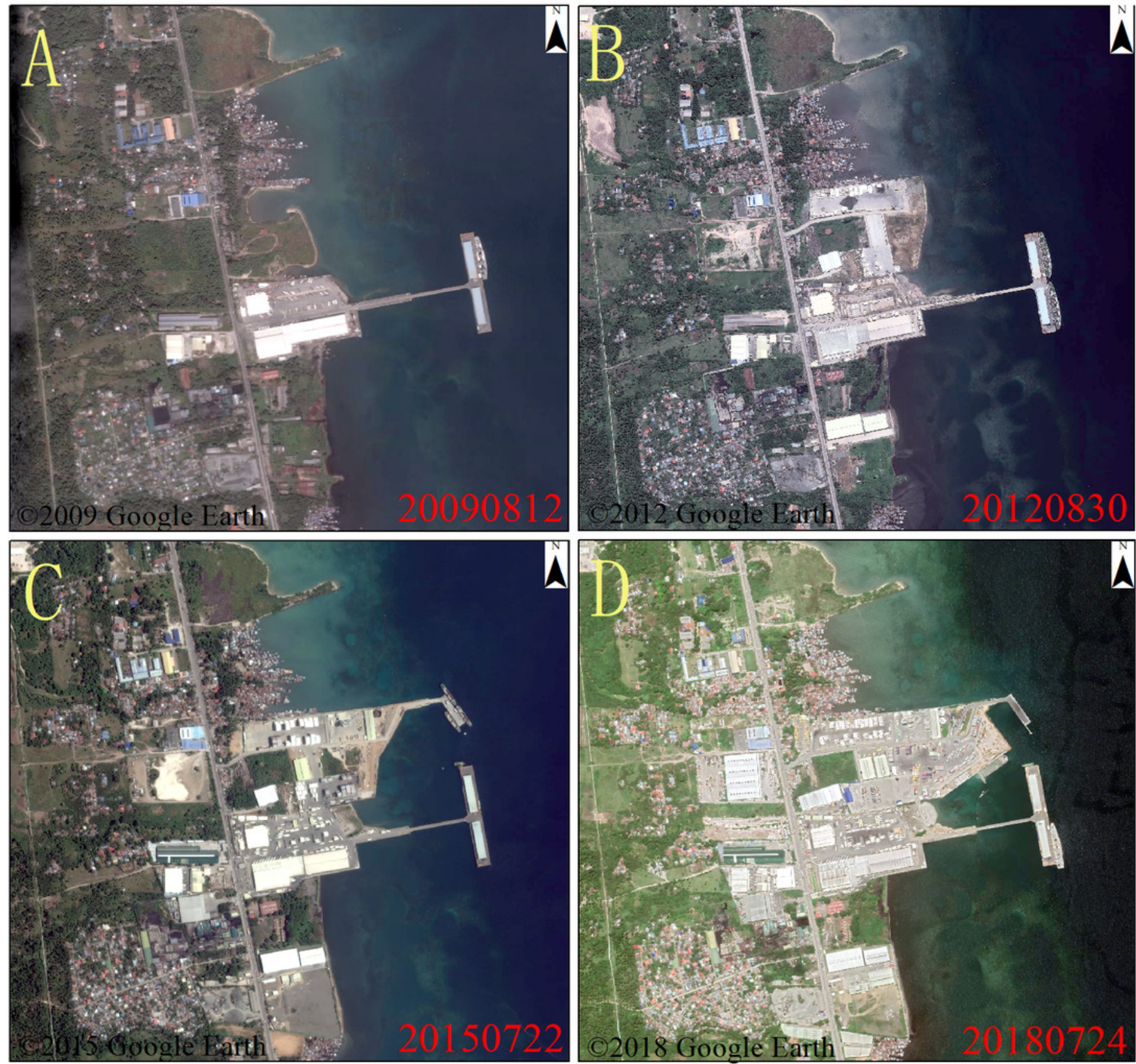

Legend

Port area in 2009

New port area in 2012
New port area in 2015

New port area in 2018
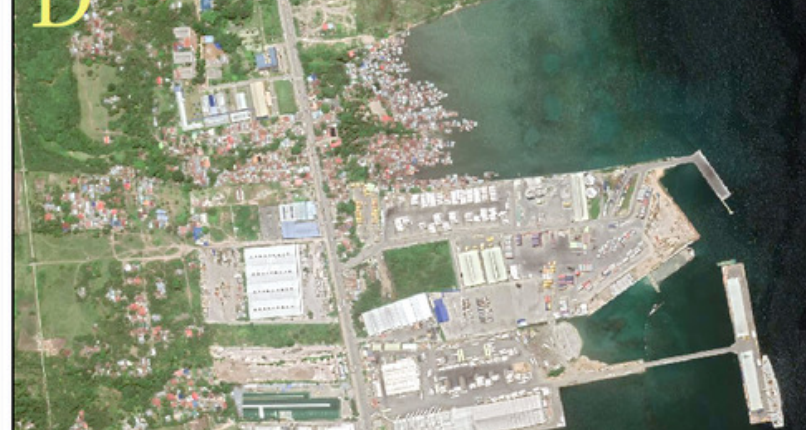

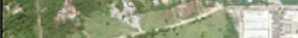

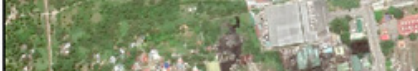

1 1 int

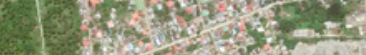

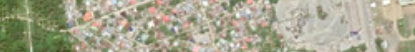

C2018 Google Earth

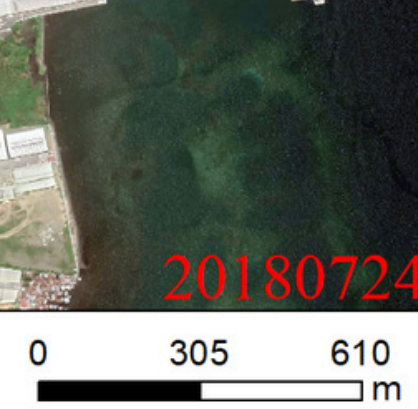


Figure 5

Land use change map of the study area in 2009(A), 2012(B), 2015(C) and 2018(D)
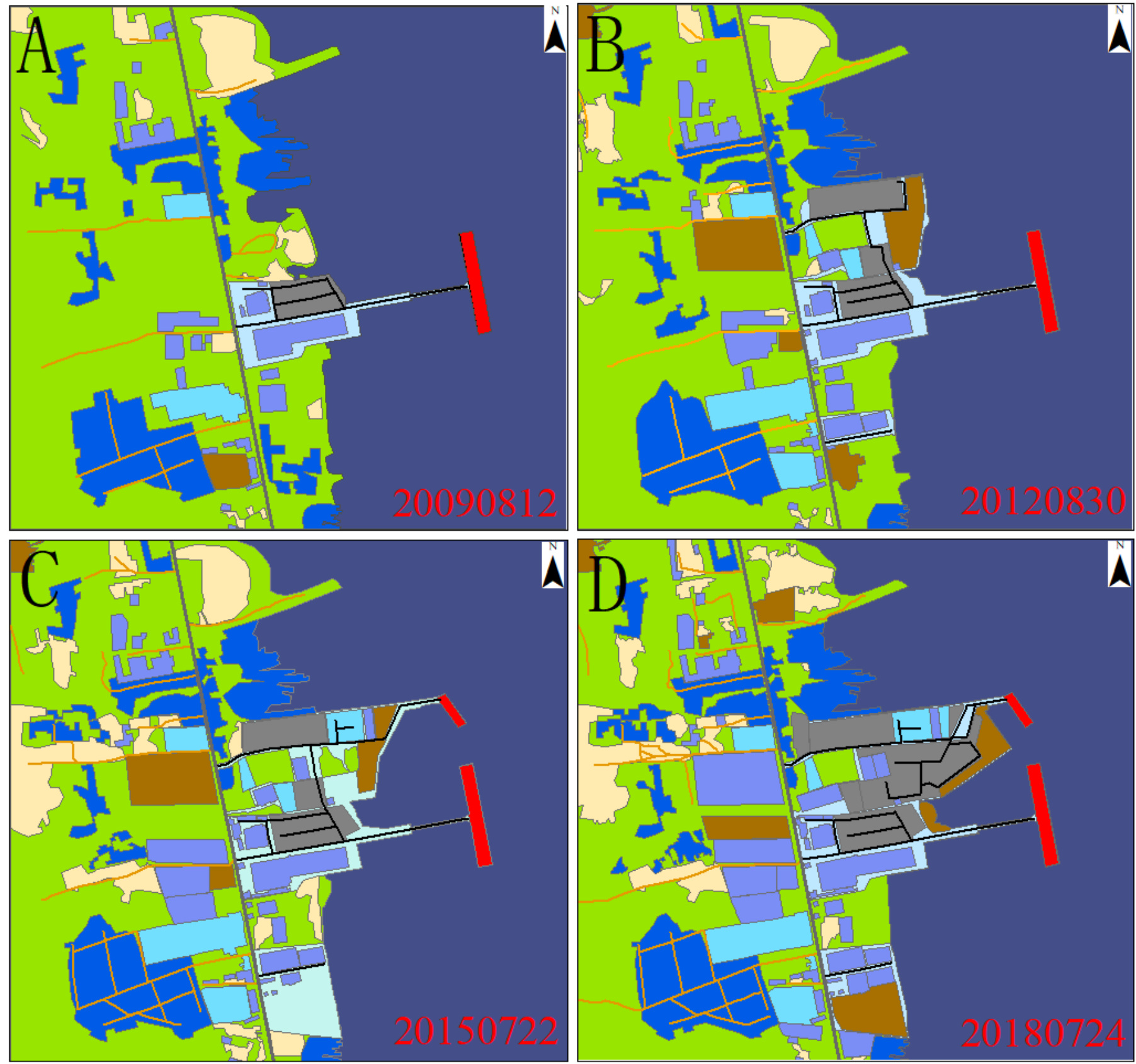

\section{Legend}

- Dirt road $\square$ Port area

- Cement road $\square$ Green area

Container yard Residential area

- Road within the port

Construction area
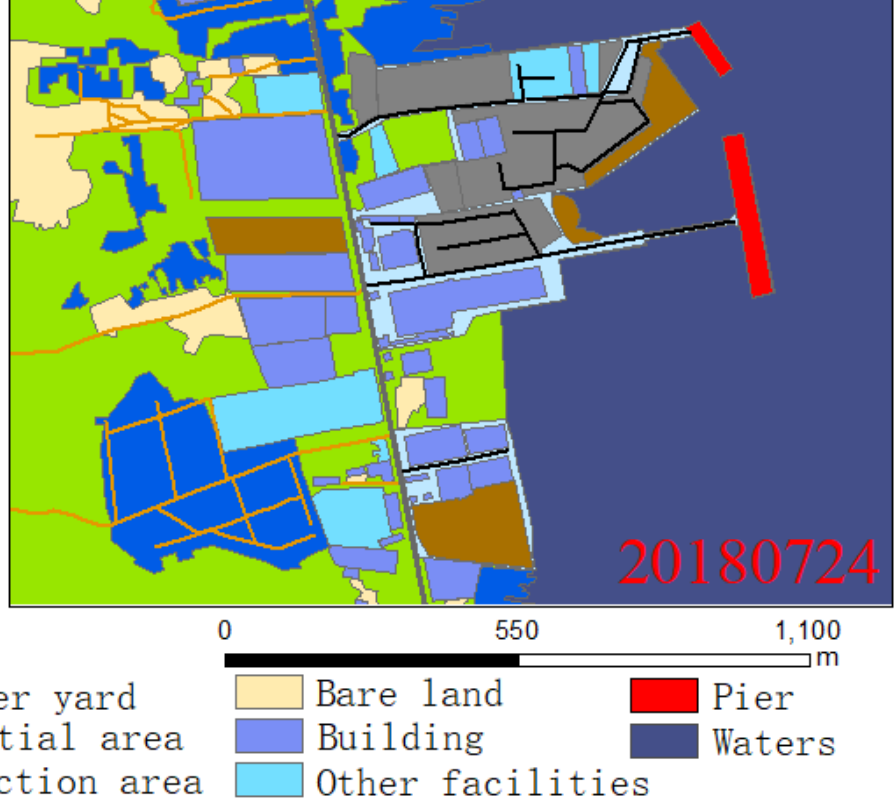


\section{Figure 6}

\section{Vegetation coverage accuracy verification map}

Five sets of samples of vegetation coverage accuracy verification map in 2009(A\&B, C\&D, E\&F, G\&H, I\&J), Five sets of samples of vegetation coverage accuracy verification map in $2018(K \& L, M \& N, O \& P, Q \& R, S \& T)$

(A, C, E, G, I): @2009 Google Earth, (B, D, F, H, J): 2009 Landsat imagery courtesy of NASA Goddard Space Flight Center, (K, M, O, Q, S): @ 2018 Google Earth, (L, N, P, R, T): 2018 Landsat imagery courtesy of NASA Goddard Space Flight Center
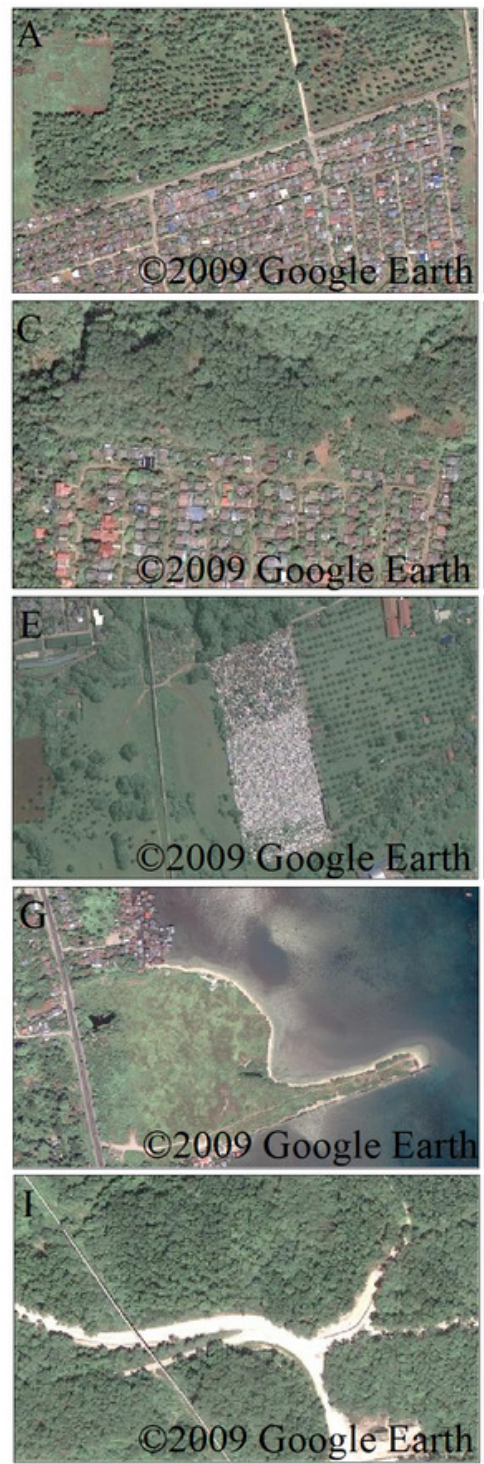

Legend
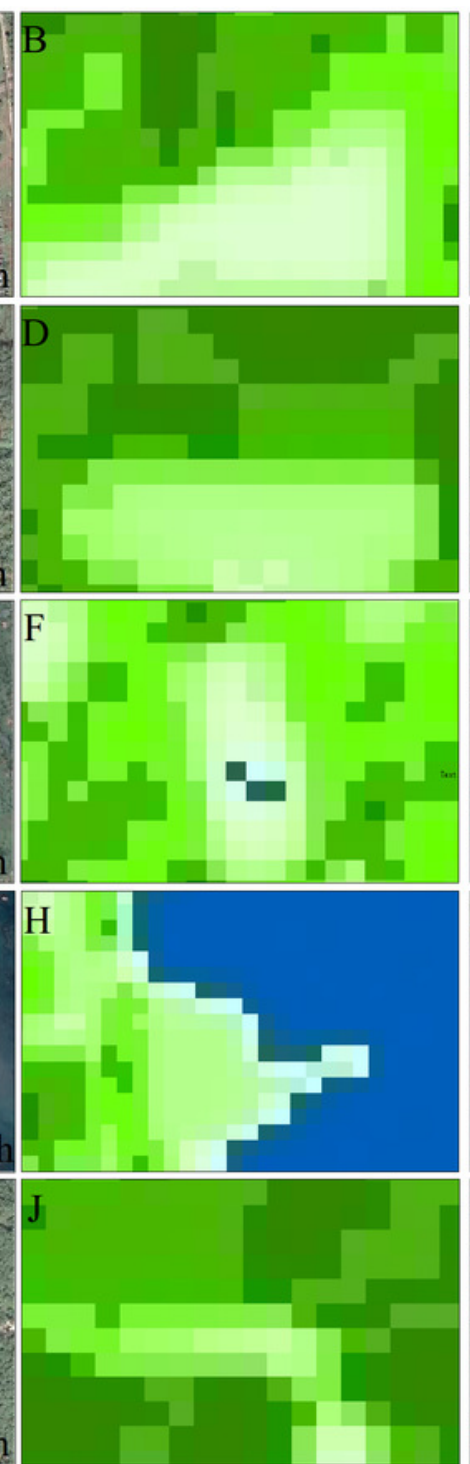

$0.2-0.4$
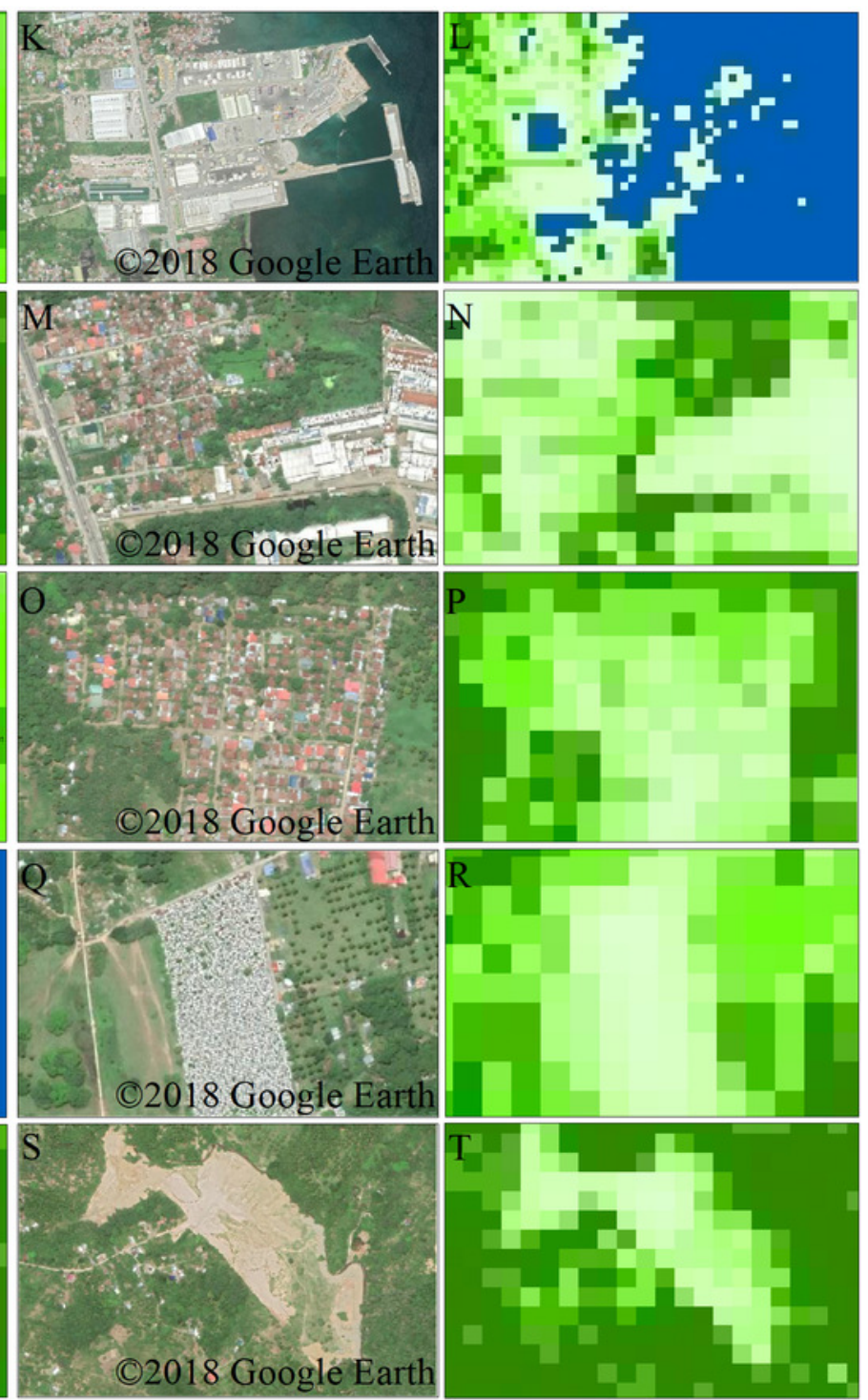

$0.6-0.8$
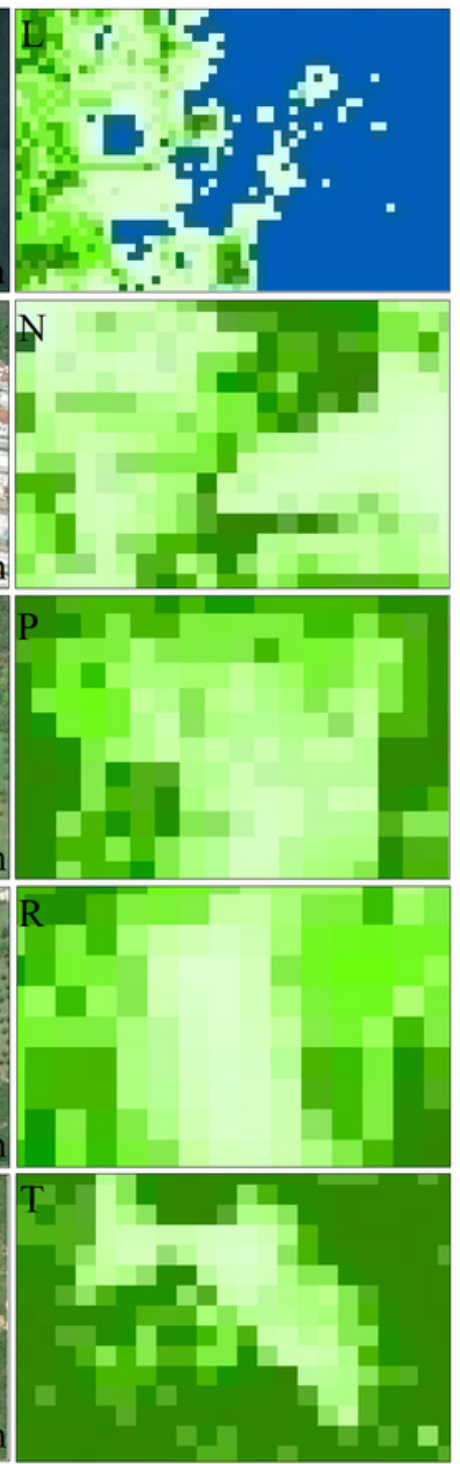

$0.9-1$ 


\section{Figure 7}

Vegetation coverage map for 2009 (A) and 2018 (B)

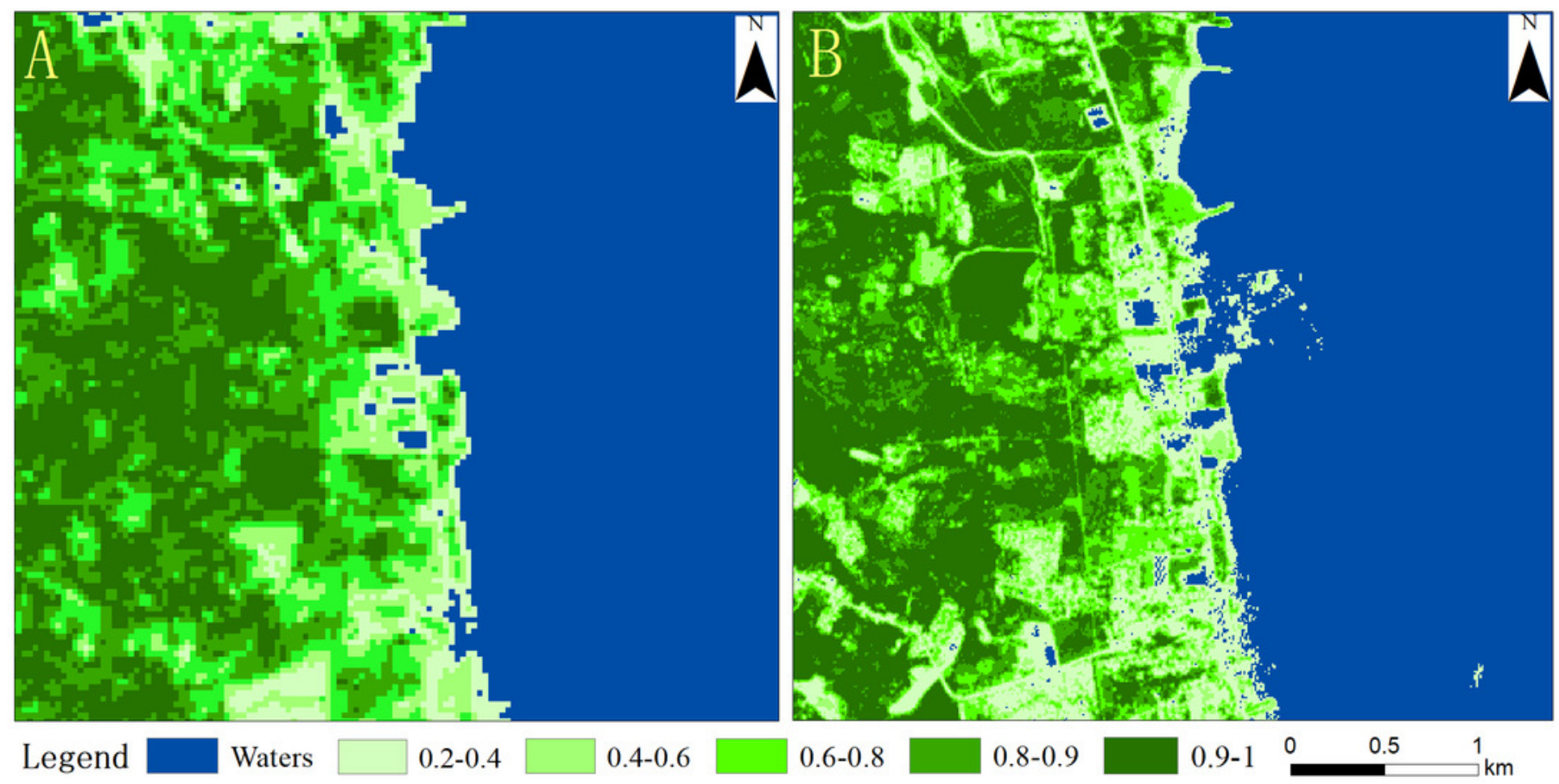


Figure 8

Port road and building change map for 2009(A) and 2018(B)

A: @2009 Google Earth, B: @2018 Google Earth

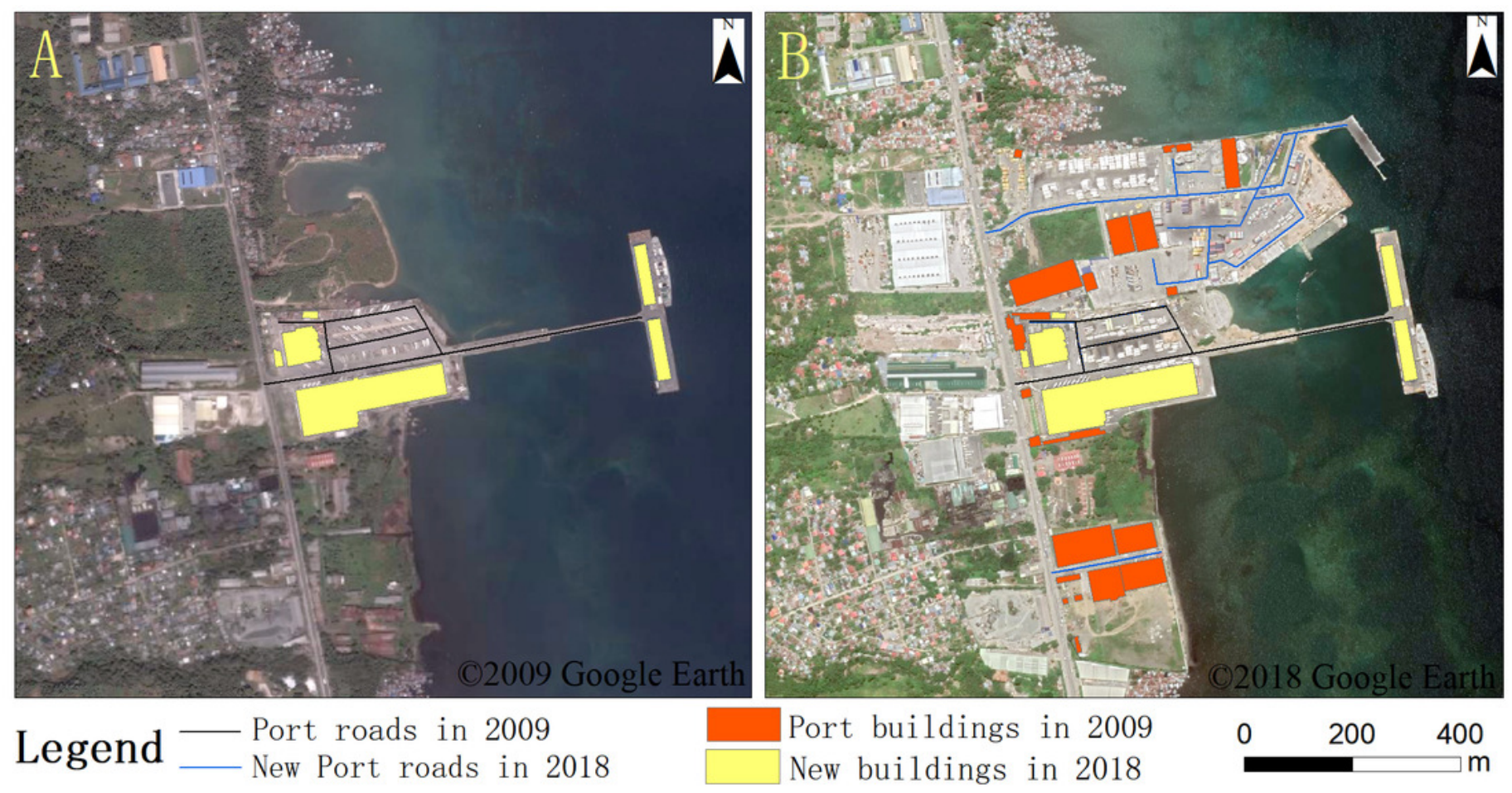


Figure 9

Davao City, Panabo City and Ajmr Port light change curve in 2009-2018

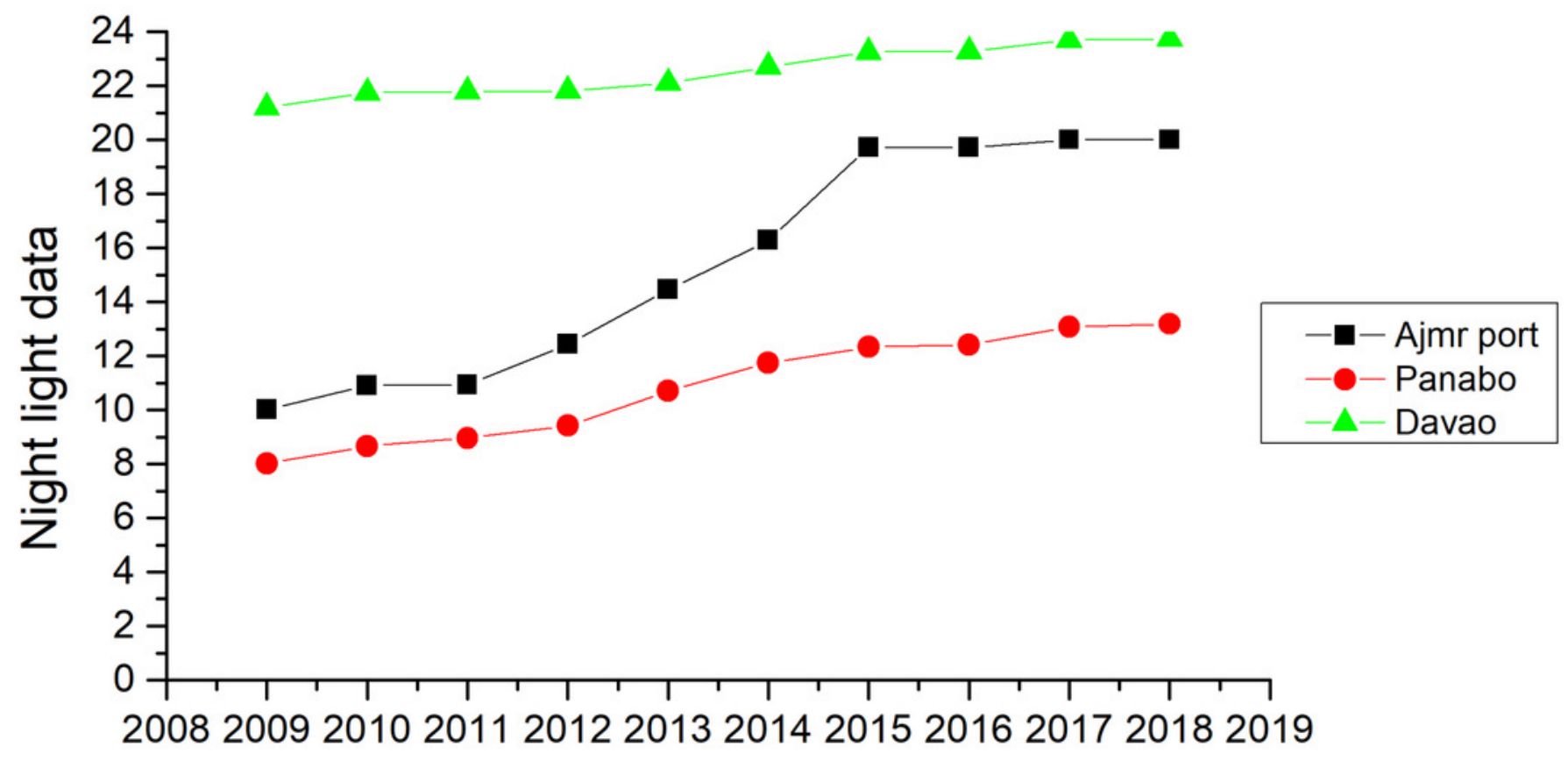


Figure 10

Growth chart of the surrounding lights of the port in 2009-2018

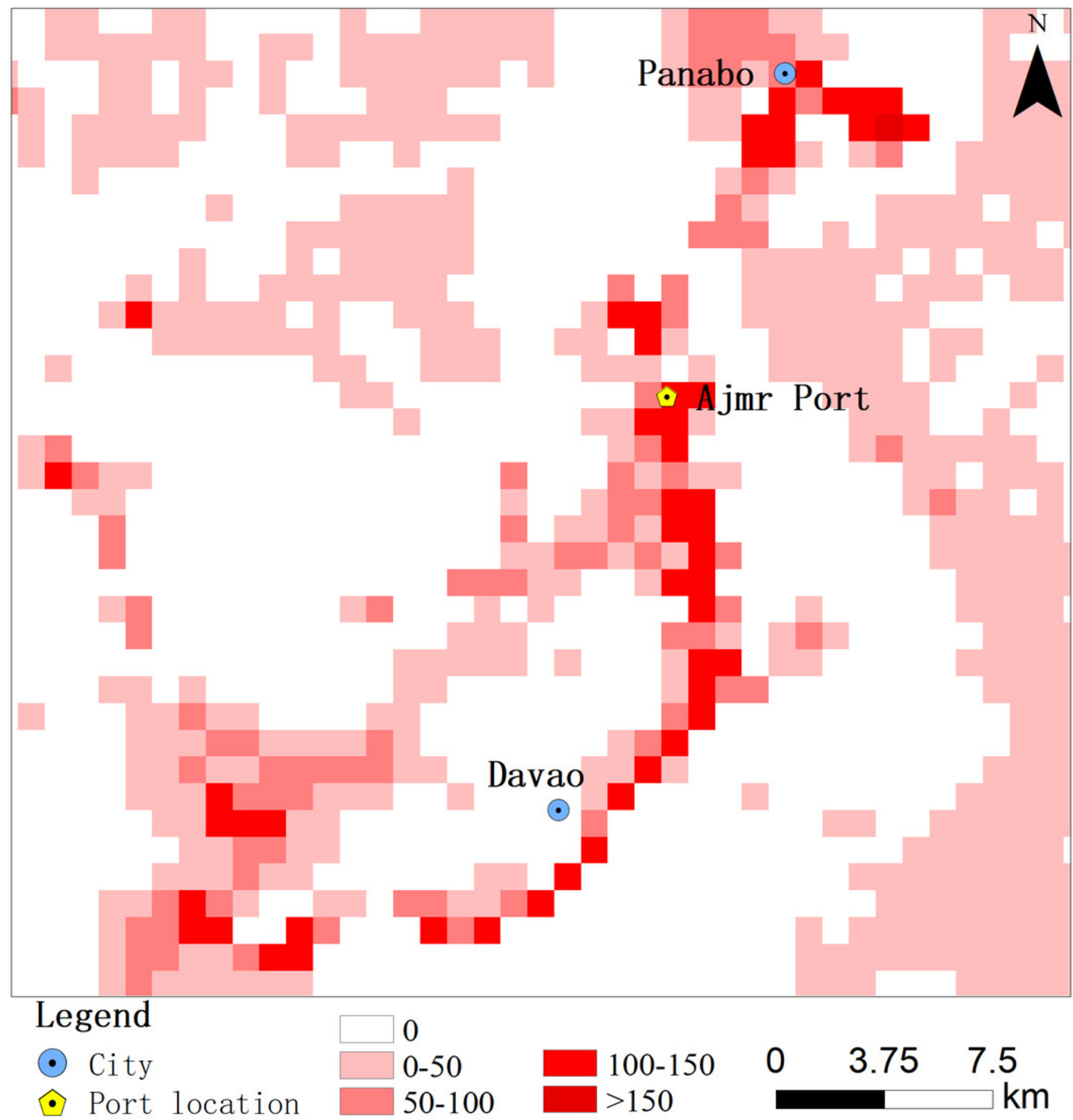

